\title{
Adaptação para Jogo de Baralho
}

\section{Adaptation for Card Playing}

\author{
Johanna Noordhoek ${ }^{(1)}$, Luiz Fabio Machado Barbosa ${ }^{(2)}$
}

Uma das deformidades mais comuns e incapacitantes em adultos com artrite reumatóide (AR) é a em pescoço de cisne, que consiste em flexão das articulações metacarpofalangianas (MCF), hiperextensão das articulações interfalangiadas proximais (IFP) e flexão das articulações interfalangianas distais (IFD) $)^{(2)}$.

A deformidade em pescoço de cisne tem várias causas, sendo a mais comum o encurtamento dos músculos intrínsecos. Essa deformidade pode ser secundária à sinovite em uma das articulações citadas, sendo mais comum nas MCF. Acredita-se que a sinovite crônica nas MCF causa espasmo muscular e, conseqüente, contratura nos músculos intrínsecos, que, associada à hipermobilidade da articulação IFP, pode resultar em flexão na articulação MCF e hiperextensão da articulação $\operatorname{IFP}^{(1)}$.

Funcionalmente, o encurtamento dos músculos intrínsecos contribui para as limitações da mão, reduzindo a destreza manual, pois a hiperextensão da articulação IFP impede que as pontas dos dedos toquem o polegar ${ }^{(2)}$. Assim, fica impossibilitada a preensão em pinça, o que limita o paciente a usar somente a pinça lateral. Além disso, pode diminuir a habilidade de pegar objetos grandes, já que impossibilita a flexão de IFP e IFD, enquanto as MCF estão em extensão.

Os músculos lumbricais e os interósseos são chamados, em conjunto, de intrínsecos, sendo que uma ação importante deste grupo de músculos é a manutenção da posição intrínseco plus (Figura 1). Na posição intrínseco plus, os interósseos e lumbricais agem juntos para promover extensão de IFP com flexão de MCF. Nessa posição, os músculos estão ativamente contraídos e em seu comprimento mais curto. Esta posição deve ser evitada em pacientes com AR que já apresentam pescoço de cisne ou em seu estágio inicial, pois a contração vigorosa e contí-

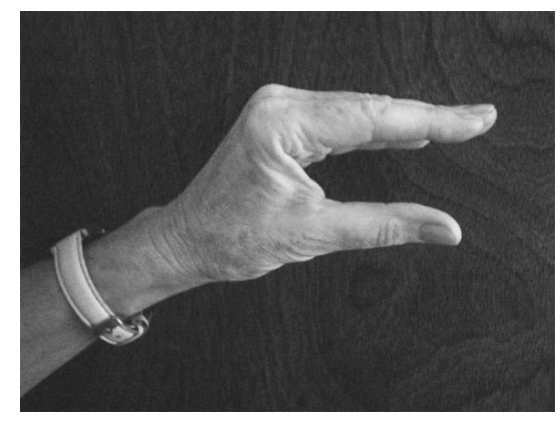

Figura 1 - Posição intrínseco plus.

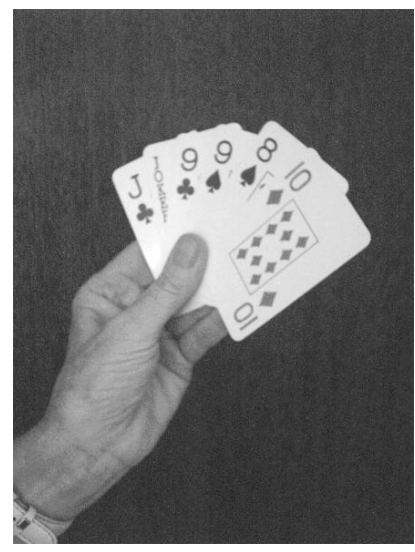

Figura 2 - Posição estática para segurar as cartas.

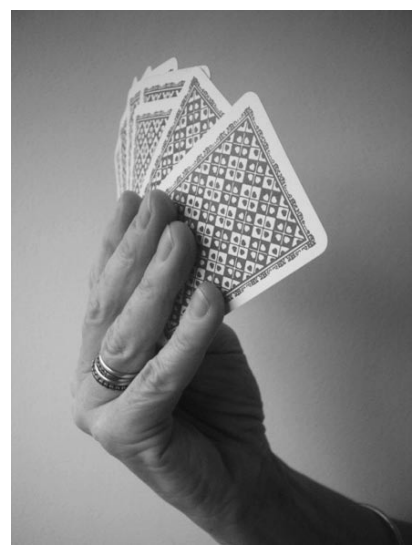

Figura 3 - Posição estática para segurar as cartas. nua destes músculos tende a favorecer o mecanismo desta deformidade $^{(1)}$. Um exemplo prático é a manutenção da posição de segurar as cartas de baralho (Figuras 2 e 3 ).

Um dos métodos utilizados para reduzir a força deformante no pescoço de cisne é evitar a permanência prolongada na posição intrínseco plus. A adaptação

1.Terapeuta ocupacional, professora do Departamento de Terapia Ocupacional da Escola de Educação Física, Fisioterapia e Terapia Ocupacional da Universidade Federal de Minas Gerais (UFMG).

2. Terapeuta ocupacional. 
apresentada vai ao encontro desse objetivo, já que através da mudança do método de realização da atividade pode facilitar sua participação no lazer (Figuras 4 e 5 ). O objeto também segue um dos princípios da abordagem terapêutica de proteção articular, que é evitar permanecer em

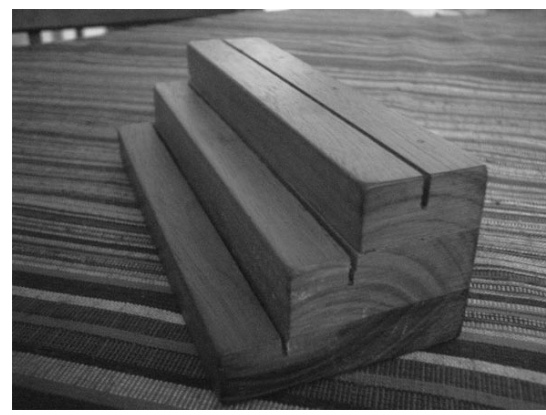

Figura 4 - Vista lateral da adaptação.

\section{REFERÊNCIAS}

1. Melvin JL: Rheumatic Disease: Occupational Therapy and Rehabilitation. 2 ${ }^{\mathrm{a}}$ ed, Philadelphia: Davis Company, cap 21, 1982 .

2. Melvin JL, Jensen GM: Rheumatologic Rehabilitation Series - Volume 1: Assessment and Management. The American uma posição estática durante muito tempo e posições e movimentos que propiciem o surgimento e o agravamento de deformidades ${ }^{(3,4)}$.

Declaramos a inexistência de conflitos de interesse.

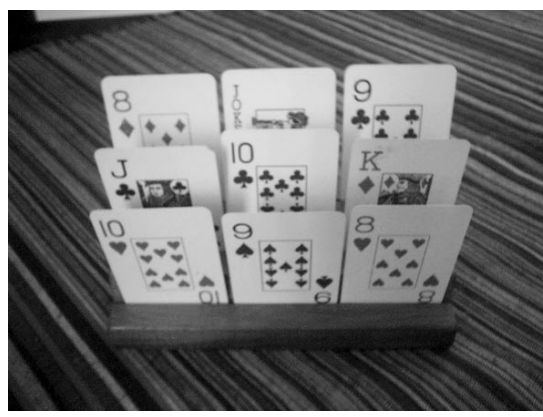

Figura 5 - Adaptação com as cartas de baralho.

Occupational Therapy Association, cap.12, 1998.

3. Nordenskiöld U, Althoff B, Hansen A: Joint Protection - for Activeling Guide. Stockholm: The Swedish Rheumatism Association, 1994.

4. Palmer P, Simons J: Joint protection: A Critical Review. British J Occupational Therapy 54: 453-8, 1991. 